Bangladesh J. Pl. Breed. Genet., 23(2): 15-22, 2011

\title{
GENETIC VARIABILITY AND SELECTION RESPONSE TO HEAT TOLERANCE THROUGH MEMBRANE THERMOSTABILITY IN SPRING WHEAT (Triticum aestivum $\mathrm{L}$ )
}

\author{
N. C. D. Barma, M. A. Islam ${ }^{1}$, M. A. Hakim ${ }^{2}$ and D. K. R. Sarker ${ }^{3}$ \\ Wheat Research Centre \\ Bangladesh Agricultural Research Institute \\ Gazipur 1701, Bangladesh
}

\begin{abstract}
The present investigation was undertaken to study the genetic variability and selection response of heat tolerance measured through membrane thermostability (MTS) in $\mathrm{F}_{2}$ derived $\mathrm{F}_{4}$ and $\mathrm{F}_{5}$ generations of five wheat crosses: Kanchan $\times$ Gourab, Gourab $\times$ Fang 60 , Kanchan $\times$ Pavon 76 , Gourab $\times$ Pavon76 and Fang $60 \times$ Pavon76. Each cross was consisted of 65, 60, 77, 72 and $64 \mathrm{~F}_{4}$ bulks including two parents. The study was conducted both in the field and laboratory of Wheat Research Centre, Dinajpur during 2002-03 and 200304. A completely randomized design for laboratory experiment and randomized complete block design for field experiments was followed with three replications. Acquired thermal tolerance through Membrane Thermo-stability assay was performed in controlled environment as per method described by Ibrahim and Quick (2001). Other morpho-physiological traits were measured from field experiment. The crosses Kanchan $\times$ Gourab, Kanchan $\times$ Pavon 76 and Fang $60 \times$ Pavon 76 showed high genetic variability with high population mean for MTS in $\mathrm{F}_{4}$ bulks. These crosses also exhibited high-observed response to selection, realized heritability and heritability in standard unit indicating expected good gain through early generation selection. Direct response to selection for this trait was significant in these crosses in $F_{5}$ generation. Direct selection for MTS significantly improved biomass, grain yield, thousand grain weight, grain filling rate and canopy temperature depression in crosses Kanchan $\times$ Pavon 76, Gourab $\times$ Pavon76 and Fang $60 \times$ Pavon76 with few exceptions Direct selection of MTS also improved chlorophyll retention at 21 days after anthesis in crosses Gourab $\times$ Fang 60 and Gourab $\times$ Pavon76. Significant intergeneration correlations $\left(\mathrm{F}_{4}\right.$ vs. $\left.\mathrm{F}_{5}\right)$ were observed for MTS in all five crosses studied indicating possibility of effective improvement of this trait through selection in early generation.
\end{abstract}

Key words: Membrane thermostability, selection response, realized heritability, intergeneration correlation.

\section{INTRODUCTION}

Wheat is the second most important cereal in Bangladesh next to rice, where wheat is being grown in a relatively less cool than temperate climate and short winter. The minimum mean temperature in the coolest month (January) ranges from $17-19^{\circ} \mathrm{C}$. It is 1-2 degrees hotter in December and February and 5-6 degrees hotter in March than

\footnotetext{
1 Department of Genetics and Plant Breeding, Bangladesh Agricultural University, Mymensingh ${ }^{2}$ Wheat Research Centre, BARI, Nashipur, Dinajpur and ${ }^{3}$ JIBIKA-CLP, Kurigram
} 
February. Depending on mean temperature of the coolest month and altitude, Fischer and Beyerlee, (1991) defined the winter of Bangladesh as hot environment in global perspective. About $80-85 \%$ of wheat in Bangladesh is grown in rotation with T. aman rice of which about $60 \%$ planted late due to delayed harvesting of rice.

Late planted wheat often encounters high temperature stress during grain filling period causing significant yield reduction. There is a potential yield decline @ 1.3\% per day when sown beyond optimum time in Bangladesh condition (Saunders, 1988). Heat stress has been given the top research priority by major wheat growing regions of the developing world including Bangladesh (CIMMYT 1995). Membrane thermostability (MTS) is an important physiological mechanism of heat tolerance in spring wheat and responsible for the adaptation of plants to high temperature (Blum, 1988). Heat damage to the plasma membrane destroys membrane integrity causing solute leakage from the cells and the extent of which may be estimated by conductometric measurement of electrolyte leakage of solute from leaf tissue after a heat shock. Membrane thermostability is a fair index of genetic variation for heat tolerance and has a reasonable relationship to plant performance under heat stressed environment and is, therefore, considered as a possible selection criterion for heat tolerance (Blum et al., 2001). Several authors also used MTS test to study genetics of heat tolerance in wheat (Saadalla et al., 1990b, Balota et al., 1993; Reynolds et al., 1994; Fokar et al., 1998a and Ibrahim and Quick, 2001) and suggested that MTS bioassays can be used to screen genotypes for heat tolerance at seedling stage in the laboratory after heat shock treatment. Membrane thermostability could also be used as early generation selection criteria to identify high yielding genotypes among segregating generations under irrigated high temperature environments. Significant genetic variation and high broadsense heritability in MTS was reported by Fokar et al. (1998a). They also observed positive and significant correlation between MTS at seedling stage and yields of these cultivars in each of four hot environments in Mexico, Sudan, India and Brazil. In a separate study with two heat tolerant and three heat sensitive genotypes, Fokar et al. (1998b) observed highly significant negative association between reduction in grain weight (RGW) and MTS at seedling and flowering stage. Ibrahim and Quick (2001) evaluated $F_{3}$ plants and their $F_{4}$ progeny derived from two crosses involving heat tolerant and heat sensitive genotypes to study the genetic variability for heat tolerance measured by MTS. Therefore, the present study was undertaken to determine the genetic variability and selection response for MTS as a measure of heat tolerance in $F_{2}$ derived $F_{4}$ and $F_{5}$ generations in five crosses of wheat.

\section{MATERIALS AND METHOD}

\section{Genetic variability of MTS in $\mathrm{F}_{\mathbf{4}}$ generation}

The $\mathrm{F}_{2}$ derived $\mathrm{F}_{4}$ progenies of five crosses were used in this experiment to study the genetic variability of MTS as a measure of heat tolerance. Five crosses i.e. Kanchan x Gourab, Kanchan x Pavon 76, Gourab x Fang 60, Gourab x Pavon 76 and Fang 60 x Pavon 76 were included in this study. Among the parents, Kanchan, Gourab and Fang 60 were moderately tolerant to heat stress and Pavon 76 was heat sensitive. The number of progenies in each cross along with the parents was $65,60,77,72$ and 64 . The study was conducted in the laboratory and field of Wheat Research Centre, Dinajpur, during 200203. A completely randomized design for laboratory experiment and randomized complete block design for field experiment with three replications was followed. Unit plot size for field experiment was $1.5 \mathrm{~m} \mathrm{x} 4$ rows for $\mathrm{F}_{4}$. The collected data were analyzed 
statistically for ANOVA using computer based statistical package MSTAT-C. Acquired thermal tolerance through Membrane Thermo Stability assay was performed with 8-10 days old seedlings under controlled environment following method described by Ibrahim and Quick (2001a). Field data were collected on biomass (BM), grain yield (GY), grain filling rate (GFR), canopy temperature depression (CTD), chlorophyll retention at 21 DAA (CHL 21), 1000-grain weight (TGW), days to anthesis and physiological maturity from field experiments. Middle 2 rows were harvested at ground level to estimate biomass $\left(\mathrm{g} \mathrm{m}^{-2}\right)$, grain yield $\left(\mathrm{g} \mathrm{m}^{-2}\right)$ and grain filling rate $\left(\mathrm{g} \mathrm{m}^{-2} \mathrm{~d}^{-1}\right)$. The mean data of MTS were ranked using EXCEL program and top 20 bulks were selected for growing next year as $F_{5}$ progenies. Genetic parameters such as genotypic and phenotypic coefficients of variation and heritability in broad sense were estimated according to the formula suggested by Burton (1951). Genetic advance in percentage of mean (GA \%) was calculated using $h^{2} b$ with the formula given by Comstock and Robinson (1952).

\section{Selection response for $\mathrm{MTS}$ in $\mathrm{F}_{2}$ derived $\mathrm{F}_{5}$ bulks}

Twenty best performing $F_{5}$ bulk progenies of $F_{4}$ in respect of MTS values for each cross along with their parents were included in this study. A completely randomized design for laboratory experiment and randomized complete block design for field experiments with three replications were followed for each cross. Unit plot size for field experiment was $2.0 \mathrm{~m} \times 4$ rows for $\mathrm{F}_{5}$. The study was conducted in WRC, Dinajpur, during 2003-04. MTS was measured as per method described by Ibrahim and Quick (2001). Data from field experiment were collected on BM, GY, GFR, CTD, CHL 21, TGW, days to anthesis and physiological maturity. Middle 2 rows were harvested at ground level to estimate biomass $\left(\mathrm{gm}^{-2}\right)$, grain yield $\left(\mathrm{gm}^{-2}\right)$ and grain filling rate $\left(\mathrm{gm}^{-2} \mathrm{~d}\right.$ $\left.{ }^{1}\right)$. Selection response for MTS was estimated according to Falconer and Mackay (1996) as follows:

Selection Differential $(\mathrm{Sd})=\left[\overline{\mathrm{F}}_{4}(\mathrm{~s})-\overline{\mathrm{F}}_{4}\right]$.

Predicted Response (PR) $=\left[\left\{\overline{\mathrm{F}}_{4}(\mathrm{~s})-\overline{\mathrm{F}}_{4}\right\} \times \mathrm{xh}^{2} \mathrm{~b}\right]$

Observed Response (in actual units) $=\left[\overline{\mathrm{F}}_{5}-\overline{\mathrm{F}}_{4}\right]$

Percent Observed Response

$$
=\frac{\text { Observed response }}{\text { Predicted response }} \times 100
$$

where, $\overline{\mathrm{F}}_{4}(\mathrm{~s})$ = Mean of 20 selected $\mathrm{F}_{4}$ families grown in 2002-03

$\overline{\mathrm{F}}_{4} \quad=$ Unselected $\mathrm{F}_{4}$ mean

$\overline{\mathrm{F}}_{5} \quad=\mathrm{F}_{5}$ mean for MTS grown in 2003-04

$\mathrm{h}^{2} \mathrm{~b}=$ broad sense heritability in $\mathrm{F}_{4}$

Realized Heritability

$=\frac{\text { Observed response in } \mathrm{F}_{5}}{\mathrm{Sd} \mathrm{in} \mathrm{F}_{4}} \times 100$

\section{Intergeneration Correlation}

The correlation coefficients between $\mathrm{F}_{3}$ and $\mathrm{F}_{4}$ generations for the selected traits of each cross were calculated by the method of Croxton et al. (1968). The intergeneration correlation coefficients after multiplying with 100 gave rise to heritability in standard unit (Frey and Horner, 1957). 


\section{RESULTS AND DISCUSSION}

\section{Genetic Parameters}

All the six crosses showed a wide range of variation among their $F_{4}$ bulk population for membrane thermostability (Table 1). The frequency distributions of MTS value for the $\mathrm{F}_{4}$ bulks of the five crosses (not shown in the paper) exhibited normal and continuous distribution for MTS indicating involvement of more number of genes in controlling this trait. All the five crosses showed transgressive segregation in both directions for this trait that indicated contribution of complementary genes from the parents. The estimates of different genetic parameters e.g. mean, range, genotypic coefficient of variation (GCV), phenotypic coefficient of variation (PCV), broad sense heritability $\left(h^{2} b\right)$, genetic advance (GA) for high temperature tolerance through membrane thermostability (MTS) in $\mathrm{F}_{2}$ derived $\mathrm{F}_{4}$ bulks of five crosses are shown in Table 1. The highest population mean for this trait was observed in cross Gourab $\times$ Pavon 76, followed by cross Gourab $\times$ Fang 60 and Kanchan $\times$ Pavon 76. The $F_{4}$ bulks evaluated in crosses Gourab $\times$ Fang 60 and Gourab $\times$ Pavon 76 exhibited relatively low genotypic and phenotypic coefficient of variation (GCV \& PCV) and moderate estimate of broad sense heritability for MTS. The rest four crosses showed high estimates of heritability and also high GCV and PCV. Almost similar results were reported in bread wheat by Reynolds et al. (1994), Shanahan et al. (1990) and Saadallah et al. (1990b) in different crosses of wheat. The genetic advance in percent of mean was the highest in cross Fang $60 \times$ Pavon 76 followed by the crosses Kanchan $\times$ Gourab, and Kanchan $\times$ Pavon 76. These crosses also had high population mean accompanied with high GCV and PCV, high broad sense heritability and high GA in percent of mean. Therefore, selection of genotypes with high MTS would result in significant progress in these three crosses in subsequent generations.

Table 1. Genetic variability high temperature tolerance through Membrane thermostability (MTS) in $F_{2}$ derived $F_{4}$ bulks of five wheat crosses.

\begin{tabular}{llccccccc}
\hline SL & Crosses & Mean \pm SE & Range & GCV & PCV & $\mathrm{h}^{2} \mathrm{~b}$ & $\begin{array}{c}\text { GA } \\
\text { GA }(\% \text { of } \\
\text { mean })\end{array}$ \\
\hline 1 & Kanchan $\times$ Gourab & $45.76 \pm 3.16$ & $29.72-60.55$ & 12.14 & 14.80 & 67.36 & 12.14 & 14.80 \\
2 & Gourab $\times$ Fang 60 & $48.45 \pm 3.00$ & $36.83-59.91$ & 7.96 & 11.00 & 52.41 & 7.96 & 11.00 \\
3 & Kanchan $\times$ Pavon 76 & $46.73 \pm 3.11$ & $35.75-60.89$ & 11.39 & 14.01 & 66.11 & 11.39 & 14.01 \\
4 & Gourab $\times$ Pavon 76 & $52.42 \pm 3.42$ & $40.99-69.22$ & 8.71 & 11.83 & 54.23 & 8.71 & 11.83 \\
5 & Fang 60 $\times$ Pavon76 & $42.64 \pm 3.36$ & $27.10-65.40$ & 17.57 & 20.01 & 76.80 & 17.57 & 20.01 \\
\hline
\end{tabular}

Table 2. Genotypic $\left(r_{g}\right)$ and phenotypic $\left(r_{p}\right)$ correlations of MTS with six morpho-physiological traits in $F_{2}$ derived $F_{4}$ bulks of five wheat crosses

\begin{tabular}{|c|c|c|c|c|c|c|}
\hline Traits correlated & & Cross- 1 & Cross -2 & Cross -3 & Cross-4 & Cross -5 \\
\hline \multirow[t]{2}{*}{ BM vs. MTS } & $r_{g}$ & $0.43 * *$ & $0.52 * *$ & $0.28 *$ & $0.34 * *$ & $0.55 * *$ \\
\hline & $r_{p}$ & 0.22 & $0.26^{*}$ & 0.12 & 0.20 & $0.28 *$ \\
\hline \multirow[t]{2}{*}{ GW vs. MTS } & $r_{g}$ & $0.35^{* *}$ & $0.50 * *$ & $0.39 * *$ & $0.50 * *$ & $0.49 * *$ \\
\hline & $r_{p}$ & 0.23 & $0.29 *$ & 0.22 & $0.30 *$ & $0.28 *$ \\
\hline \multirow[t]{2}{*}{ TGW vs. MTS } & $r_{g}$ & $0.26 *$ & -0.11 & 0.22 & $0.33 * *$ & $0.38 * *$ \\
\hline & $r_{p}$ & 0.14 & -0.17 & 0.19 & 0.22 & $0.30 *$ \\
\hline \multirow[t]{2}{*}{ GFR vs. MTS } & $r_{g}$ & 0.18 & $0.50 * *$ & $0.38 * *$ & $0.41 * *$ & $0.46^{* *}$ \\
\hline & $\mathrm{r}_{\mathrm{p}}$ & 0.13 & $0.30 * *$ & 0.21 & $0.25^{*}$ & $0.25^{*}$ \\
\hline \multirow[t]{2}{*}{ CHL21 vs. MTS } & $r_{g}$ & $0.33 * *$ & $0.35^{* *}$ & 0.24 & $0.30 *$ & 0.12 \\
\hline & $r_{p}$ & 0.20 & 0.16 & 0.14 & 0.13 & 0.09 \\
\hline \multirow[t]{2}{*}{ CTD vs. MTS } & $r_{g}$ & $0.27 *$ & $0.34 * *$ & $0.33 *$ & 0.062 & $0.32 *$ \\
\hline & $r_{p}$ & 0.16 & 0.19 & 0.21 & 0.08 & $0.25 *$ \\
\hline $\mathrm{N}=$ & & 65 & 77 & 60 & 72 & 64 \\
\hline
\end{tabular}




\section{Genotypic and phenotypic correlation of MTS with few other traits}

MTS showed significant correlation with biomass, grain yield and grain filling rate in most of the crosses at genotypic and phenotypic levels (Table 2). Many investigators (Saadalla et al. 1990a; Fokar et al. 1998a \& 1998b) reported highly significant correlation of MTS measured at seedling stage with grain weight and grain yield. Blum et al. (2001) in a study with 79 recombinant inbred lines observed high and positive correlation between MTS and biomass and between MTS and grain yield. TGW and CTD showed highly significant positive correlation with MTS both at genotypic and phenotypic levels in the cross 5 only. In a few cases, CHL 21 and CTD also showed significant positive correlation with MTS but only at genotypic level. It was observed that the genotypic correlations were higher in magnitude than the corresponding phenotypic values in all the five crosses. Sometimes, the correlation between traits was found non-significant at phenotypic level but significant at genotypic level. It indicated that the inherent relationship of two traits sometimes was suppressed by the environmental influence at phenotypic level reducing correlation coefficients. The results of the present study suggested the potential use of this trait (MTS) as indirect selection criteria in selecting for grain yield under heat stress situation in early generation.

\section{SELECTION RESPONSE}

\section{Heritability and Observed Response for MTS in F $_{5}$ Generation}

Selections were made for high membrane thermostability (MTS) in $\mathrm{F}_{4}$ generation and the selected bulks were evaluated in replicated tests in $\mathrm{F}_{5}$. The observed and predicted responses to selection for MTS in the $F_{5}$ generation for five crosses are presented in Table 3. The results also revealed variation among the crosses for selected and unselected $\mathrm{F}_{4}$ mean, selection differential (SD) and heritability in $\mathrm{F}_{4}$. So, predicted and observed response also varied among the crosses. The result also indicated a positive improvement in $\mathrm{F}_{5}$ mean for MTS through selection in $\mathrm{F}_{4}$ generation.

Table 3. $F_{4}$ selected mean, $F_{4}$ mean, selection differential, heritability, $F_{5}$ mean and Predicted and Observed response in $F_{5}$ generation for Membrane thermostability (MTS) of five wheat crosses

\begin{tabular}{cccccccc}
\hline Crosses & $\overline{\mathrm{F}}_{4} \mathrm{~S}$ & $\overline{\mathrm{F}_{4}}$ & $\mathrm{SD}(\mathrm{S})$ & $\mathrm{h}^{2} \mathrm{bF}_{4}$ & Predicted Response & $\overline{\mathrm{F}_{5}}$ & Observed Response \\
\hline Cross-1 & 52.25 & 45.06 & 6.65 & 0.67 & 4.48 & 49.93 & 4.33 \\
Cross-2 & 53.54 & 48.17 & 5.37 & 0.52 & 2.82 & 50.99 & 2.82 \\
Cross-3 & 53.22 & 46.67 & 6.55 & 0.66 & 4.33 & 50.08 & 3.41 \\
Cross-4 & 57.74 & 52.29 & 5.45 & 0.54 & 2.96 & 54.90 & 2.61 \\
Cross-5 & 50.35 & 42.09 & 8.26 & 0.77 & 6.35 & 48.36 & 6.27 \\
\hline
\end{tabular}

Cross 1: Kanchan x Gourab; Cross 2: Gourab x Fang 60; Cross 3: Kanchan x Pavon 76

Cross 4: $\quad$ Gourab x Pavon 76; Cross 5: Fang 60 x Pavon 76

Realized heritability (in percent), heritability (in standard unit) and percent observed response are shown in Table 4. The crosses Gourab x Fang 60 and Kanchan x Gourab exhibited the highest observed response (\%) to selection followed by and Fang $60 \mathrm{x}$ Pavon 76. However, all the five crosses exhibited moderate to high observed response (78.94 to $101.08 \%$ ). The estimates of realized heritability based on $30 \%$ selection intensity, varied from cross to cross. The highest realized heritability was estimated in cross Kanchan x Gourab, followed by Fang 60 x Pavon 76 and Gourab x 
Fang 60. The estimate of broad sense heritability was also high in these crosses. Higher estimate of heritability in these three crosses indicated that good gain could be made for this trait through early generation selection. The other three crosses showed low to moderate realized heritability for this trait. In the present study, the estimates of heritability in standard unit were generally higher or closer to the realized heritability estimates in all the crosses studied indicating good efficiency of selection for MTS in these crosses. Ibrahim and Quick (2001) observed relatively intermediate (0.47) realized heritability for MTS based on $15 \%$ selection intensity in bread wheat.

Table 4. Estimates of heritability in standard unit, realized heritability and observed responses (as percent of the predicted responses) for MTS in $F_{5}$ bulks of five wheat crosses

\begin{tabular}{clccc}
\hline $\begin{array}{c}\text { Cross } \\
\text { no. }\end{array}$ & \multicolumn{1}{c}{ Crosses } & $\begin{array}{c}\text { Heritability in } \\
\text { Standard unit }(\%)\end{array}$ & $\begin{array}{c}\text { Realized } \\
\text { Heritability }(\%)\end{array}$ & $\begin{array}{c}\text { Observed } \\
\text { Response }(\%)\end{array}$ \\
\hline 1 & Kanchan $\times$ Gourab & 67.36 & 80.45 & 101.04 \\
2 & Gourab $\times$ Fang 60 & 52.41 & 62.20 & 101.08 \\
3 & Kanchan $\times$ Pavon 76 & 66.11 & 52.06 & 78.94 \\
4 & Gourab $\times$ Pavon 76 & 54.23 & 47.89 & 88.78 \\
5 & Fang 60 $\times$ Pavon 76 & 76.80 & 75.91 & 98.58 \\
\hline
\end{tabular}

\section{Direct and Indirect Responses}

Direct response to selection for MTS was positive and significant (in actual unit) in all the crosses except crosses Gourab x Fang 60 and Gourab x Pavon 76 (Table 5). Direct response to selection for this trait was the highest in cross Fang 60 x Pavon 76 followed by cross Kanchan $\mathrm{x}$ Gourab. Selection for MTS caused significant improvement for BM and GY in crosses- Gourab x Fang 60, Gourab x Pavon 76 and Fang $60 \mathrm{x}$ Pavon 76. Indirect response to selection for MTS was also significant and positive for TGW in three crosses (Kanchan x Pavon 76, Gourab x Pavon 76 and Fang $60 \mathrm{x}$ Pavon 76). Direct selection for MTS also brought about significant improvement for grain filling rate in all the crosses except Kanchan x Gourab. Fokar et al. (1998b) reported highly significant positive association between grain weight and MTS at seedling and flowering stage under heat stress condition.

Table 5. Direct (underlined) and indirect responses (in actual units) due to selection of membrane thermostability (MTS) in $\mathbf{F}_{5}$ generation of five wheat crosses

\begin{tabular}{lcccccccc}
\hline \multicolumn{1}{c}{ Crosses } & $\begin{array}{c}\text { Traits Selected } \\
\text { for }\end{array}$ & $\begin{array}{c}\text { MTS } \\
(\%)\end{array}$ & $\begin{array}{c}\text { Biomass } \\
\left(\mathrm{g} \mathrm{m}^{-2}\right)\end{array}$ & $\begin{array}{c}\text { Grain wt. } \\
\left(\mathrm{g} \mathrm{m}^{-2}\right)\end{array}$ & $\begin{array}{c}\text { TGW } \\
(\mathrm{g})\end{array}$ & $\begin{array}{c}\text { GFR } \\
\left(\mathrm{g} \mathrm{m}^{-2} \mathrm{~d}^{-1}\right)\end{array}$ & $\begin{array}{c}\text { CHL21 } \\
(\mathrm{Spad})\end{array}$ & $\begin{array}{c}\text { CTD } \\
\left({ }^{\circ} \mathrm{C}\right)\end{array}$ \\
\hline Kanchan x Gourab & MTS(\%) & $\underline{5.29^{*}}$ & $22.08^{*}$ & 7.81 & 0.57 & 0.13 & 0.50 & 0.06 \\
Gourab x Fang 60 & MTS(\%) & $\underline{3.24}$ & $24.25^{*}$ & $10.25^{*}$ & -0.24 & $0.38^{*}$ & $0.71^{*}$ & 0.07 \\
Kanchan x Pavon 76 & MTS(\%) & $\underline{5.03^{*}}$ & 13.95 & 9.38 & 0.77 & $0.28^{*}$ & 0.32 & $0.08^{*}$ \\
Gourab x Pavon 76 & MTS(\%) & $\underline{3.90}$ & $21.23^{*}$ & $13.31^{*}$ & 0.68 & $0.28^{*}$ & $0.70^{*}$ & 0.02 \\
Fang 60 x Pavon 76 & MTS(\%) & $\underline{7.62^{*}}$ & $38.11^{*}$ & $13.94^{*}$ & $1.27^{*}$ & $0.40^{*}$ & 0.32 & $0.09^{*}$ \\
\hline
\end{tabular}

$*, * *$ indicate significance at $5 \%$ and $1 \%$ level, respectively

Direct selection for MTS significantly improved CHL 21 in two crosses (Gourab x Fang 60 and Gourab x Pavon 76) and CTD in crosses Kanchan x Pavon 76 and Fang $60 \mathrm{x}$ Pavon 76. Among the traits, CHL 21 and CTD were less influenced by direct selection of MTS. The low genotypic correlation between MTS and these two traits might be reason for low indirect response. The result indicated considerable direct response to selection for MTS in cross Fang 60 x Pavon 76 associated with higher positive indirect response for most of the traits. Although direct response to selection for 
MTS was not significant in the crosses Gourab x Fang 60 and Gourab x Pavon 76 but indirect response to selection through four traits was significant and positive for MTS (Table 4). Therefore, these crosses could be exploited for improving MTS through direct and indirect selection. Blum et al. (2001) also reported high and positive correlation of MTS with biomass and grain yield in bread wheat. Ibrahim and Quick (2001a) also observed sufficient realized heritability for MTS to predict good progress to selection in the crop, especially if more replications are used and if selection being applied in advanced generations.

\section{$\mathbf{F}_{4}-\mathbf{F}_{5}$ Intergeneration Correlation}

The success of early generation selection usually depends on high correlation between the performance of the genotypes selected in one generation and the performance of their progeny in the following generation. In the present study, significant intergeneration correlations $\left(\mathrm{F}_{4}\right.$ vs. $\left.\mathrm{F}_{5}\right)$ were observed for MTS in all five crosses studied (Table 6) suggesting efficiency of selection. Similar findings for MTS were also reported by Ibrahim and Quick (2001a).

Table 6. Intergeneration correlation $\left(F_{4}\right.$ vs. $\left.F_{5}\right)$ for MTS in five wheat crosses

\begin{tabular}{clc}
\hline SL.\# & \multicolumn{1}{c}{ Crosses } & r-value \\
\hline 1 & Kanchan $\times$ Gourab & $0.52 *$ \\
2 & Gourab $\times$ Fang 60 & $0.47 *$ \\
3 & Kanchan $\times$ Pavon 76 & $0.50^{*}$ \\
4 & Gourab $\times$ Pavon 76 & $0.45^{*}$ \\
5 & Fang 60 $\times$ Pavon 76 & $0.52^{*}$ \\
\hline
\end{tabular}

* Indicate significance level at $0.05, \mathrm{~N}=20$.

Genetic variability, selection response, direct and indirect response to selection and significant intergeneration correlation revealed that direct selection for MTS could be effective to improve this trait through selection in early generation and consequently to select heat tolerant genotypes in successive generations.

\section{REFERENCES}

Balota, M., I. Amani, M. P. Reynolds, and E. Acevedo, 1993. Evaluation of membrane thermostability and canopy temperature depression as screening tools for heat tolerance in wheat. Wheat Special Report \# 20. Mexico, D.F.; CIMMYT.

Blum, A. 1988. Plant Breeding for stress environments. CRC Press, Inc., Boca Raton, Florida.

Blum, A. N. Klueva and H. T. Nguyen. 2001. Wheat cellular thermotolerance related to yield under heat stress. Euphytica. 117(2): 117-123.

Burton, G. W. 1951. Quantitative inheritance in pearl millet (Pennisetum glaucum). Agron. J. 43: 409-417.

CIMMYT, 1995. CIMMYT/NARS Consultancy on ME1 Bread Wheat Breeding. Wheat Special Report No. 38. CIMMYT, Mexico, D. F.

Comstock, R. E. and H. F. Robinson. 1952. Estimation of average dominance of genes. In "Heterosis" Ed. G. W. Gowen. IOWA State Cillege Press, Ames, IOWA: 494516.

Croxton, F. E. and D. J. Cowden and S. Klein. 1968. Applied General Statistics. London, Sir Isac Pitman and Sons Ltd. pp. 1-754. 
Falconer, D. S and T. F. C. Mackay. 1996. Introduction to Quantitative Genetics. Longman Ltd., England.

Fischer, R. A. and D. Byerlee. 1991. Trends of wheat production in the warmer areas: Major issues and economic considerations. In: D. A. Saunders Ed.) Wheat for the Non-Traditional Warm Areas. Proc. of Conference, Iguazu, Brazil, July 29-Aug. 3, 1990. PP. 3-27. CIMMYT, Mexico D. F.

Fokar, M., H. T. Nguyen, and A. Blum. 1998a. Heat tolerance in spring wheat. I. Genetic variability and heritability of cellular thermotolerance. Euphytica. 104: 1-8.

Fokar, M., A. Blum, and H. T. Nguyen. 1998b. Heat tolerance in spring wheat II. Grain filling. Euphytica 104(1): 9-15.

Frey, K. J. and T. Horner. 1957. Heritability in standard unit. Agron. J. 49: 59-62.

Ibrahim, A. M. H.and Quick, J. S. 2001. Heritability of heat tolerance in winter and spring wheat. Crop Sci. 41: 1401-1405.

Reynolds, M. P., M. Balota, M. I. B. Delgado, I. Amani and R. A. Fischer. 1994. Physiological and morphological traits associated with spring wheat yield under hot, irrigated conditions. Aust. J. Pl. Physiol. 21: 717-30.

Saadalla, M. M., J. F. Shanahan and J. S. Quick. 1990a. Heat tolerance in winter wheat. I. Hardening and genetic effects on membrane thermostability. Crop Sci. 30(6): 1243-1247.

Saadalla, M. M., J. S. Quick and J. F. Shanahan. 1990b. Heat tolerance in winter wheat. II. Membrane thermostability and field performance. Crop Sci. 30(6): 1248-1251.

Saunders, D. A. 1988. Crop management research: Summary of results, 1983-88. Monograph No. 5: Wheat Research Center, Dinajpur, Bangladesh.

Shanahan, J. F.; J. B. Edwards; J. S. Quick and J. R. Fenwick. 1990. Membrane thermostability and heat tolerance of spring wheat. Crop Sci. 30: 247-251. 